\title{
Article \\ Multilingualism in Migrant Contexts in Pakistan and the UK: Transcending Physical, Social and Symbolic Borders in Transnational Social Spaces
}

\author{
Tony Capstick (D)
}

check for

updates

Citation: Capstick, Tony. 2021. Multilingualism in Migrant Contexts in Pakistan and the UK: Transcending Physical, Social and Symbolic Borders in Transnational Social Spaces. Languages 6: 177. https://doi.org/ 10.3390/languages6040177

Academic Editors: Jaine Beswick, Darren Paffey, Juana M. Liceras and Raquel Fernández Fuertes

Received: 8 February 2021

Accepted: 14 October 2021

Published: 25 October 2021

Publisher's Note: MDPI stays neutral with regard to jurisdictional claims in published maps and institutional affiliations.

Copyright: (C) 2021 by the author. Licensee MDPI, Basel, Switzerland. This article is an open access article distributed under the terms and conditions of the Creative Commons Attribution (CC BY) license (https:// creativecommons.org/licenses/by/ $4.0 /)$.
Department of English Language and Applied Linguistics, University of Reading, Reading RG6 6AF, UK; tony.capstick@reading.ac.uk

\begin{abstract}
This paper is based on a four-year ethnographic study of multilingualism in transnational Mirpuri families in Azad Kashmir (Pakistan) and Lancashire (United Kingdom). Data were collected in a range of physical settings in Pakistan and the UK as well as social spaces online. Migrants' literacy practices are often related to the standard language variety of the country to which the migrant is moving. However, this paper suggests that migration requires different kinds of literacies, not all of which relate to standard writing system use. The study sought to understand how these literacies are shaped in Pakistan before they are taken up in the UK, by seeing them as part of migrants' everyday translanguaging. This perspective involves exploring how different language varieties (such as Punjabi, Urdu and English) and different linguistic resources (such as scripts, styles and registers) are appropriated by migrants at different stages of their migration trajectories alongside migrants' own perspectives on these practices. The findings demonstrate how migrant families counter discrimination in their everyday multilingualism as part of the translingual practices which transcend physical, social and symbolic borders.
\end{abstract}

Keywords: transnational social spaces; translanguaging; identity practices

\section{Introduction}

In Pakistan, poverty limits access to literacy in the national language, Urdu, and the official language, English (Ayres 2009). Since agreements in the 1950s between the British and Pakistan governments encouraging men and their families from Azad Kashmir, Pakistan, to migrate to the UK to fill the labour shortages in northern textile factories, strong transnational networks have developed between the two countries as a means to overcome some of the constraints Mirpuris face in education and employment in Pakistan. Mirpur, in Pakistan-administered Kashmir, and Lancashire, in the north west of England, are bound together by these intergenerational trajectories of migration, the third phase of which, known as marriage migration, is at the core of the study presented here as we explore the literacy practices of transnational family members in Pakistan and the UK. Seeing literacy in this way means seeing reading and writing as a shared resource, put to use by members of multilingual communities to fulfil a range of social purposes (Blommaert 2008; Capstick 2016a, 2016b). The current paper seeks to extend this approach by focusing on literacy practices that circulate in countries of origin as well as countries of settlement. Hanks (2005, p. 191) suggested that the lens of practices helps re-think the relation between language and context by integrating the two 'while overcoming the debilitating dichotomy between local and large-scale contexts'. Following Kell (2009) in a previous study, I sought to bridge this dichotomy by tracing how meaning making shifts across space and time when working with large amounts of ethnographic data from Pakistan and the UK (Capstick 2020). I found that events would often link to other events and that this interconnectedness revealed the constraints of single-instance analysis. In the present study, I continued to explore how 
meaning making shifted from moment to moment and across spaces in Pakistan and the UK by incorporating a translanguaging lens on these literacy practices.

In Pakistan, formal literacy in Mirpur is in Urdu since British colonial rule. Mirpuri Punjabi is the language spoken at home in Mirpur (Lothers and Lothers 2007), though it is not a language that was written down to any great extent until social media began to provide the affordances for the creation of romanised scripts for Punjabi. These scripts are taken up alongside non-standard varieties for Urdu and English as online interactants choose which varieties they use and how they wish to use them. This use is always shaped by the socio-historical and political processes of which these practices are part (Warriner 2007). The present study focused on how these transnational relationships are sustained in the translingual practices of friends and family online in order to identify what a transnational optic reveals about migration, social inclusion, and unbounded understandings of the nation-state (Vertovec 2009; Levitt 2015). These contemporary discussions about transnationalism emerged from the work of Linda Basch and colleagues whose initial argument was based on the de-territorialized nation-state (1994), later developed by Smith and Guarnizo's Transnationalism From Below (1998) to encompass in which the everyday activities and actions of families are contrasted with the circulation of global finance and business. This kind of transnationalism from below is illustrated in the transnational literacies explored in the study presented here and was also a central feature of Warriner's (2007) work on transnational literacies in which she connected everyday literacy practices to multi-stranded social relations across two or more nation-states. For Warriner, literacy practices maintain as well as transform these social relations just as they transform identities. In this sense, transnational literacies form part of the social capital which Portes et al. (1999), drawing on Bourdieu (Bourdieu and Nice 1980), considered provides privileged access to resources for the transnational family.

The question I ask in this paper is what happens to these identities when Pakistani migrants go online and use a different script for Urdu and create their own writing systems for Mirpuri Punjabi? In Pakistan, Punjabi was rarely used in a written form as a language until the affordances of digital media enabled this. In the UK, where minority language varieties are often undervalued and proficiency in English is associated with national identity, what identities are marked by the use of English alongside Urdu and Mirpuri Punjabi? In this paper, I look beyond proficiency in the 'national' language to investigate how, when writing online, migrants select language features from across their repertoires or rather 'call upon different social features in a seamless and complex network of multiple semiotic signs' (Garcia and Kano 2014, p. 261). These multiple semiotic signs can, for example, be seen in their writing in digital environments as migrants take up the affordances of new media to help them deploy their resources for different purposes and with different people. In this way, migrants remain connected to multiple localities and communities (Androutsopoulos 2014) by working out, with others and by themselves, how these different resources can or cannot help them remain connected before and after their migrations. In order to explore how this community of users establish conventions for Urdu and Mirpuri and choose when to stick to or deviate from these conventions online, this study looked at the ways that writing systems are connected to prior language use in chains of communication (Bakhtin 1981). Bakhtin's $(1981,1994)$ concept of heteroglossia helps account for the mixing of different voices in migrants' translanguaging in digital environments as the analysis of multiple social voices and languages reveals how all utterances are 'many tongued', that is, their dialogism applies to the mutual influence of these various utterances (Bakhtin 1981). Androutsopoulos (2014, p. 8) argued that tensions and contrasts between linguistic resources, social identities and ideologies are not only part of the situated nature of computer-mediated discourse but that different languages explicitly index different identities while at the same time being 'moulded together' into particular posts in interactive digital environments. Migrants, particularly those who have just arrived in their new host country, must continually mould together the resources that are available to them as they use social media to stay in touch with family and friends in 
the country they have left while also building relationships in their new home. It is this capacity of the de-/re-territorialized speaker to create new social spaces that Li Wei and Hua located at the centre of a translanguaging approach to examining the dynamic nature of multilingual practices (2013) because of their ability to mobilize different features from their repertoires.

In this article, I focus on the multilingual practices of Usman, a nineteen-year-old Pakistani migrant from Mirpur, Azad Kashmir, who, at the time of data collection, had recently arrived in the UK after having married Nadia, a 27-year-old British-Mirpuri woman from Lancashire. The data I consider in this article come from Facebook interactions between Usman and his friends and family members back in Pakistan which he engaged in after he had arrived in the UK and interviews in which he described other everyday literacies. In these interactions, a range of semiotic resources and new practices of hybridity can be seen, practices that involve the strategic mixture of multiple resources in ways that open up for Usman new communicative possibilities, which, in this case, help him to manage his new identities as a migrant.

\section{Theoretical Framework}

In this study, the notion of translanguaging was brought together with the social practices approach to the study of literacy and writing systems. Sebba made the case for the link between New Literacy Studies and writing systems when he stated the importance of the latter to the former because of its focus on practices and the socio-cultural aspects of these practices rather than seeing literacy as simply a skill (Sebba 2009, p. 36). This approach sees literacy practices as ideological as they involve values, feelings and social relations (Street 1984; Barton and Hamilton 1998). Taking a practices approach, Lillis suggested that any specific instances of writing are built out of existing semiotic resources which are not free-floating but are tied to conventions such as genres (Lillis 2013, p. 101). In turn, these instances of writing are also part of discursive regimes (Fairclough 1992) or what Blommaert described as literacy regimes in which access to and distribution of literacy resources are tied to social relations (Blommaert 2008, p. 6). This distribution is explored by turning to the users of literacy to understand the relationship between views about writing and its usage. Often this meant focusing on talk-like elements of the social media postings of migrants which in many respects reflect the spoken discourse of these participants. By focusing on the choices that the users of written language make with respect to their writing systems, the paper draws attention to the extent to which writing online is shaped by migrants' everyday translanguaging and, in this sense, draws on Lewis and Fabos's (2008) study on talk-like elements of instant messaging. Speech is not seen in binary opposition to writing, but rather the aim is to account for what writing is and does without taking a categorical view (Lillis 2013).

To explore how migrants from Pakistan like Usman draw on these relations and resources for writing required a framework that sought to identify the particular uses of such resources and how they are mediated by families and friends. Accounting for this mediation meant exploring the language resources which Usman brought with him to the digital genres of Facebook and how he mixed the conventions of standard and non-standard Punjabi, Urdu and English and negotiated different degrees of freedom and constraint with respect to the writing systems available. It also meant exploring Usman's own perspective on these practices and how he felt they related to his migration. Thus, the approach to integrating a sociolinguistic approach to writing systems into the translanguaging lens proposed here requires a theoretical framework that is able to account for these multiple perspectives on migrants' literacies, including their own perspectives. This framework is well-served by ethnography, grounded as it is in epistemological principles from sociology and anthropology which focus on the emic perspective of insiders' on their own practices (Bloome 2012, p. 10). This approach, therefore, is based on multiple data sets, the roles of which are explained at the end of this section as the analysis of the different voices in these 
data are as central to the analysis as the analysis of the different voices in the Facebook texts, to which I next turn.

The notion of translanguaging is relevant to studying the complex and hybrid multilingual practices that transnational migrants such as Usman develop and use. In contrast to code switching, which refers simply to a shift between two languages, translanguaging foregrounds speakers', and in this study, writers', use of interrelated discursive practices that Garcia and Wei suggested cannot be easily assigned to one or another traditional definition of language but instead are assembled from the users' total repertoire (Garcia and Wei 2014, p. 22). For Li Wei, viewing multilingualism through the lens of translanguaging space emphasizes the capacity of the multilingual individual as an active agent in social life, while for Canagarajah (2013), translingual literacies are not about fashioning a new kind of literacy, but rather they are about understanding the practices and processes that already characterize communicative activity in diverse communities. These conceptualisations of writing and translanguaging have been put to work in developing the academic writing of bilinguals. In the work of Velasco and Garcia (2014) and Garcia and Gaddes (2012), we see how effective language learning that includes translanguaging strategies requires enactment within a meaningful context which in turn facilitates the processing of linguistic and writing demands (Velasco and Garcia 2014, p. 21). This is because multilingual speakers are not simply responding rationally or not to broader forces and structures but creating spaces for themselves using the resources that they have. Understanding how migrants create spaces for translanguaging resonates with Barton and Hamilton's work on the hybridity of everyday literacies (2000) which converge in the home but which can be found on the borderlands of various domains such as school and workplace. In this study, these hybrid practices were made visible in digital environments partly by users' choice of script but they are also part of the wider everyday resources that are shared across family members in a range of transnational spaces. Although the notion of translanguaging is productive in shedding light on the complexity and hybridity of multilingual practices, the focus has been on single sites in migrants' trajectories with little focus on migrants' practices and indeed own perspectives on their practices prior to migration. When engaging with the hybridity in Usman's literacy practices, I noticed that he often described literacies from different domains in Pakistan and the UK when explaining his online practices in the UK (Capstick 2020). An expanded notion of translanguaging would therefore benefit from a multi-sited ethnography that moves out from the local situations and single sites to investigate the 'cultural meanings, objects, and identities in diffuse time-space' (Marcus 1995, p. 96) as Marcus first intended with multi-sited ethnography. Taking this triangulatory approach can also help account for the discrepancies, as Soler and Zabrodskaja (2017, p. 549) saw them, between speakers' actual behaviour and their linguistic ideologies when they translanguage. Rather than looking at how language management strategies may or may not coincide with actual language practices in single-site settings, the approach taken here enables a view on how users appropriate different language and literacy resources that are shaped by different ideological positions in a range of sites as they move through different physical and social spaces.

This appropriation is seen as heteroglossic because the social media texts are discursively shaped by the multiple voices that Bakhtin $(1981,1994)$ suggested can be heard in any text and which signal the ideologies and identities of those who play these voices off against each other. For Bakhtin, every word that is uttered is social, that is, it is caught up in a complex web of relationships with other speakers and writers. He suggested that it is impossible to speak without borrowing the words of others as by appropriating not only grammatical conventions but also by appropriating conventional genres and styles, speakers and writers become certain kinds of people, that is, form certain identities. This means that individuals ventriloquize the voices of those who have used these languages, genres and styles before and will do so again. Working ethnographically meant asking participants about how they use these different resources in different settings. The range of settings analysed here includes social media postings as well as home, school and work- 
places. These analyses were combined with the analysis of how voices (evident in script, styles, genres and registers) are appropriated with an analysis of how different language varieties (such as Punjabi, Urdu and English)—which are also seen as ways of invoking voices-are simultaneously appropriated in the hybrid practices of writing online. This use of the concept of heteroglossia in the analysis of script, genre, register and languages and how they are taken up in digital environments is similar to Rampton's $(1995,1998)$ work on crossing in that the focus on 'double-voicing' foregrounds the uptake of hybrid stylistic resources and the evaluation of these resources by their users. Rampton also focused on stylization and language crossing by drawing on Bakhtin's discussions of double voicing and heteroglossia in what Bakhtin called 'ideological becoming' (Rampton 2006, pp. 346-47). The dialogical processes of becoming are traced in the ways that individuals appropriate some voices while distancing themselves from others. Usman, for example, becomes an 'emigrant from Mirpur' when he combines voices when chatting with his friends online. He also becomes an 'immigrant to the UK' when he distances himself from these voices and appropriates other voices when chatting to his new relatives in a later posting. Heteroglossia offers a theoretical lens through which to identify the appropriation of these multiple voices while translanguaging refers to the linguistic practice of combining these different voices to represent who is doing what in a particular situation. Translanguaging 'gives voice to speakers in ways which allow them to activate the full range of their linguistic repertoires' (Blackledge and Creese 2014, p. 13).

Combining these different voices, which are connected to 'existing' language use, but reshaping them and their meaning when resources travel, is evidence of this expanded notion of translanguaging. Garcia (2009) suggested that translanguaging is different from other fluid language practices as it can upset hierarchical relations between different practices by reducing the status of some of these practices over others. What I needed to know was not how Usman removed these hierarchies but how he realigned them at different stages of his migration. This is because migrants invoke different voices as emigrants than they do as immigrants. Thus, by building a theoretical framework that helps trace how Usman invokes different voices at different stages, I was able to understand how Usman gives voice to the new social and political realities of his migration. Conceptualising translanguaging in this way changes our understanding of how it is 'transformative in nature' and how it enables speakers and writers to operationalise aspects of their experiences and histories (Wei 2011, p. 1223). In this approach, these are the personal histories of transnational migrants, including their experiences of migration and their literacy practices related to these experiences. The environment in this study included homes in Pakistan and the UK as Usman described how these domains shaped his literacies. Though Wei (2014) explained how translanguaging connects people to the histories, attitudes, values and ideologies that they have acquired in different circumstances, it is the lens of heteroglossia that provides the link to how these values and ideologies are made up of different voices that must first be accounted for (as heteroglossic) before they can be understood in their specific configurations as translanguaging.

Finally, it is important to explain how this framework integrates these aspects of translanguaging into a theoretical framework that also takes account of Usman's insider perspective. The highly reflexive interviews carried out with Usman where I asked him about his writing and his migration were also heteroglossic and contained other voices to those he invokes online. Usman and I appropriated the voices of the interviewer and interviewee and the different ideological positions we oriented to in our roles as researcher and researched. These social interactions were also literacy events, and heteroglossia can be traced in the hybrid voices we each appropriated. The voices Usman appropriated in these interviews helped him construct new identities while he was simultaneously engaged in the process of describing a different range of identities constructed in his Facebook postings. Examining the differences between these different data sets and the different ways Usman appropriated voices in each data set provided further insights into how he presents his migration to different interlocutors, myself included. This approach 
provides an original contribution to how we understand translanguaging as seeing these interviews as heteroglossic connects migrants' language practices to the different stages of their migrations while also providing their own insider perspective on these experiences.

\section{Transnational Migration in Pakistan and the UK}

Azad Kashmir (AK), a disputed territory in the north of Pakistan, has long been connected with Lancashire in the north west of England through chain migration: male labour, family reunion and marriage migration (Harriss and Shaw 2008). Transnational migration, often through arranged marriages, of this kind still binds towns like Mirpur in AK to the post-industrial heartlands of Lancashire and Yorkshire in the UK. These connections provide the social and virtual spaces in which to investigate the changing forms and functions of literacy and language as traditions within sociolinguistics shift with new understandings of bilingualism (Garcia and Wei 2014) while the focus of literacy studies itself shifts from the local to the translocal (Warriner 2007; Baynham and Prinsloo 2009). Thus, the discussion of migration literacies is embedded within wider debates about the links between monolingual integration policies and social cohesion which, in the UK context, often focus specifically on Mirpuris, from Azad Kashmir, and the essentialist view that third-generation Mirpuris feel only a distant connection to the ancestral culture of their grandparents (Goodhart 2013, p. 73).

By exploring how transnational literacies are markers of this distance, as well as of belonging, to the many thousands of Mirpuris living in the UK, this paper seeks to problematize the notion that it is proficiency in the language of the destination country that supports migrants' integration. In their work exploring the linguistic integration of migrants in the European Union, Wodak and Boukala (2015) established how tests of proficiency in the national language increasingly act as gate-keeping obstacles for migrants. Though migration requires these literacies (see Capstick 2016a for a full discussion), it is also necessary to explore how exactly non-standard as well as standard varieties fit into the multilingual literacy practices of migrants as it is these practices that shine a light on other forms of integration such as those linked to families' transnational relations. Li Wei and Zhu Hua argued that translanguaging is relevant to examining the multilingual practices of transnational migrants because it provides a lens on how 'everyday practices and identities are profoundly rooted in the developmental trajectories of the communities to which individuals belong' (Hua and Wei 2020, p. 520). In this paper, the linguistic resources of one extended family from Mirpur are examined alongside wider community language resources available in Azad Kashmir and the role of these varieties in the construction of new identities. This perspective rests on the notion that the identities available to individuals at a given moment in history are subject to change, like the ideologies that legitimize and value particular identities more than others (Blackledge and Pavlenko 2001). Migrants look for new social and linguistic resources that allow them to resist imposed identities while constructing alternative identities that position migrants from outside the European Economic Area more positively while enabling them to integrate into their transnational communities.

\section{Methodology}

I met Usman (19 years old at the time) and his wide circle of friends and family in Mirpur in 2010 when I was carrying out ethnographic fieldwork for my PhD study. At this time, the UK government was starting to introduce English language testing for spousal visas. As a result, English language courses had proliferated across Mirpur, most of them offering programmes aimed specifically at equipping learners with the English language skills related to fulfilling the visa requirements. Usman was applying for a visa to join Nadia (in her mid-20s at the time) in Lancashire. Nadia had visited Mirpur for only the second time in her life for just over a month earlier the same year. After meeting Usman briefly, Nadia married Usman and before returning to the UK conceived their first child who was born a few months later in the UK. Nadia's father had arrived in Britain 
in the 1960s as a male labour migrant, closely followed by his wife as part of the family reunion phase of the chain. Usman's marriage migration (which he describes as economic migration) thus forms the third phase of a chain of migration. Usman told me that he had not considered migration until his father was approached in Mirpur by relatives of Nadia's parents in the UK with the suggestion that Nadia may wish to consider Usman as a second husband after she had divorced from her cousin in Lancashire. The family had sent a video showing Usman to Nadia. She had instantly found him attractive and looked forward to meeting him when she flew to Pakistan.

Usman had already started his second visa application when I met him, hoping to join his wife and young son in Lancashire soon. Nadia's solicitor had told them that the first visa application had failed because the marriage appeared to the UKBA as a 'sham'. Usman told me that he was working hard in his second application to avoid the marriage being seen as, in his words, 'bogus'. All interviews with Usman were carried out in English. Translation of Urdu in the Facebook postings was carried out by the author while Mirpuri Punjabi translations were sent to Mirpur where L1 users of Mirpuri Punjabi were available. As the Anglo-heritage author grew up in the Lancashire towns involved in the UK ethnography, he was part-insider while very much an outsider while collecting data in Pakistan (for further discussion of researcher positionality, see Capstick 2016a).

Interviews were coded by using discourse topics about migration gathered from the wider PhD study (for a full discussion of these discourse topics see Capstick 2016a). Hillington is a pseudonym as are all of the participants' names. Interviews took place in the UK from February 2011 to August 2012 during which time Usman was using instant messaging (IM) to talk in groups as well as send private messages and update his friends using words, images and hyperlinks. For Usman, this means that he and his friends post photographs on their profile pages, give each photograph a title and make comments about the photographs in the space underneath. As I began analysing the data, I found that literacy events, such as the Facebook postings, were only a small part of the discursive trajectories of Usman's migration. Thus, in order to link the data in meaningful ways through emic descriptions (Kell 2009), I began to carry out self-report interviews with Usman in which we discussed the transcripts of the online writing but increasingly focused on where he thought the linguistic features came from. In these interviews, I showed Usman copies of the transcripts of the Facebook data and asked him what was happening at each moment in the interaction, about the language varieties being used (and why) and about the social relations between the interactants. This methodological approach is my response to the application of heteroglossia as a key orientation to prioritising the user of language (that is, the speaker or writer) rather than the language variety, which would be more common in an analysis of code switching (Heller 2007). What I mean here is that the self-report interviews provided the key participant, the language user, with the opportunity to illuminate the analysis of his language practices with his own meaning making. I take the self-report interview data also to be heteroglossic as Usman oriented to different discursive practices and invoked different voices when talking to me. Transcontextual analysis of literacy practices has been the focus for much of the third wave of literacy studies (Baynham and Prinsloo 2009). Kell in particular attempted to 'pin down' the threads that connect documents, practices and translations which allow researchers to 'pass from the local to the global' (Kell 2009, p. 86). Like Kell, when developing the methodological framework for this study, I was interested in moving beyond literacy events to track the shifts from one context to the next when analysing the discursive trajectories of the family's practices. In much the same way that Kell noted 'a person can act and feel powerful in one context at one point in time using one mode of communication, but not in another' (Kell 2009, p. 86) so too did I aim to explore the meaning-making trajectories of Usman's migration when reconstructing the ethnographic data as I felt that it was his vernacular literacies that provided him with opportunities to generate identities that were oppositional to the negative identities imposed on Pakistani migrants in the dominant discourses of the UK. This reconstruction of the ethnographic data following Kell's work on meaning-making 
trajectories was combined with a new analysis re-examining heteroglossia by introducing the work on translanguaging discussed earlier, in the online data and the interview data, which was carried out during late 2016 and early 2017. In total, 46 sets of Facebook postings including nine photographs, 12 separate instant messaging conversations, six interviews and six field-visit observational field notes were analysed for the findings reported in this study though additional data sets made up the entire original ethnography.

After downloading all the photographs and comments, I first carried out my own rough translation before sending the comments to a translator in Pakistan who added his translation of Mirpuri Punjabi. More important though in capturing the emic perspective were the detailed translations with Usman which were the first stage of our self-report interviews, and it is these translations that appear below. However, as becomes clear in the analysis, Usman's translations were not always the same as the translators' translations. During these interviews, I asked Usman about his social media practices as a way of establishing the relationship between these practices and his language and literacy practices discussed in other interviews. These self-report interviews, similar to Barton and Lee's (2013) techno-biographic interviews, were reflective in that the aim was to explore the meaning making Usman brought to his social media interactions at multiple points across his migrations. Twelve weeks after arriving in the UK, Usman had found two jobs: operating the radio at a taxi company and working in the kitchen of a fast-food restaurant. While at work, Usman continued to use his mobile telephone, purchased for him by his wife, to access the internet.

\section{Methods of Analysis}

As discussed earlier, Bakhtin (1994) suggested that it is impossible to speak without borrowing the words of others, that the appropriation of resources lies not only in borrowing lexical and grammatical conventions but also in the way that conventional genres, registers and styles of speaking are borrowed. Jones (2016, p. 45) argued that the primary purpose of such borrowing is to be recognized as being certain kinds of people doing certain kinds of things. As the aim of this paper was to establish how the community of users in this study decide how to follow or deviate from conventional standard varieties and their scripts, I chose to break down the appropriation of different voices into three analytical steps. Firstly, this meant establishing the different language varieties and how they were used in the online data. Second, I established the specific scripts, styles and registers that Usman draws on and how he described these in the interview data. This is because, Sebba argued, writing systems involve conventional relationships at multiple levels (Sebba 2009, p. 37). For this reason, Sebba contended, writing systems can be seen as social practices where entire communities of users as well as individual users first establish conventional relationships and then, in the future, decide whether to follow or deviate from the established conventions (Sebba 2009). I, therefore, chose to look at how these conventional relationships are made up of decisions about language at the level of script as well as at the levels of style and register. I did this because it is the act of choosing between these different options that constitutes the practice of writing system use, be that by adhering to prescribed standards or by deviating from those standards (Sebba 2009, p. 38). Thirdly, I sought to establish how these resources were then put to use to generate new identities which transcended one physical (e.g., UK) or social (e.g., Facebook) setting. This emphasis on generating new identities emerges from work which posits that properties of the self are dynamic and can change over time, that they are not predetermined or fixed but are open to changes, rather like masks that can be worn and taken off in different social interactions (Goffman 2002). This conceptualisation of identity provides the foundations for understanding the dynamics of self-presentation on Facebook where text-based computer-mediated interaction provides the means by which people perform and construct different features of identities through linguistic means (Barton and Lee 2013). 
When analysing these linguistic means and reconstructing the ethnographic data, the first step was to establish which language varieties were being drawn on in the online data and what Usman said about these varieties in the interviews. Early on in the comparison of Usman's translations with the translators' translations, it became evident that Usman's translations were influenced by the fact that he was translating them to me and wished to present himself and some of his interlocutors in a positive light (Capstick 2016a). Thus, when I returned to the data for the new analysis of heteroglossia in late 2016, I examined Usman's translations as heteroglossic. The properties that made Usman's translations heteroglossic relate to the different voices he chose to foreground when reformulating and recontextualising the original Mirpuri Punjabi posting into Standard British English which fit with the socio-cultural setting of an interview with me. The vernacular re-telling of how Usman looks 'spoiled' is an indication of how, when a speaker speaks the same word in a different context (that is, first on Facebook, next in an interview), it is, according to Bakhtin (1981), different and therefore heteroglossic. Moreover, when Usman uses the same word in a different chronotope or time, it is also different. Accounting for this nuance here provides further evidence of how the online data could be seen as imbued with different ideological stances. These voices are incorporated into the analysis in the present study as I not only wanted Usman to identify everyday examples of his translanguaging but I also wished to probe further into where he felt that the resources he drew on came from and how he and his interlocutors appropriated them in the immediate moment-to-moment interactions of Facebook. This meant analysing the online texts and the interview texts alongside each other and coding the features in the online data by using Usman's meaning-making descriptions from the interview data to answer the question: what linguistic resources are used, what voices are invoked and what identities does Usman generate in his Facebook postings? Usman's subjective responses and biases are included in the analysis.

In the analysis that follows, I broke down the ethnographic data collected during this period into a series of strips of approximate timescales to capture the complexity of movement in time and space as he constructs and maintains multiple belongings. I did this so that I could link what Usman was telling me in interviews about his literacy practices to what he was telling me in the interviews about his 'new' life and how the two were linked. Kell explained that each meaning-making trajectory should be seen as small threads in relation to wider sets of trajectories operating on different scales. By organizing the data into trajectories, I was able to plot Usman's movement through physical and social spaces immediately after his migration before introducing the analysis of his beliefs about his language and literacy practices. I identified the following MMTs across the six months:

MMT1: Usman arrives in Lancashire and spends time with his new family (three weeks).

MMT2: Usman spends time meeting extended family members but is mainly at home without work (seven weeks).

MMT3: Usman starts work at both a taxi company and a takeaway restaurant (one month). MMT4: Usman establishes himself at work (one month).

As can be seen from the trajectories above, literacy practices were not an end in themselves analytically but were distributed across broader sequences of events. Organizing the data into strips enabled a systematic framework for connecting the locations and timings of Usman's Facebook postings with the MMT of his arrival and experiences of settling into his new life in Lancashire (who he was meeting, where they were, and how he was feeling). For reasons of space, it is not possible to list all of the strips for all of the MMTs. The strips for MMT3 are presented here:

Strip 1: Starting work in the taxi office.

Strip 2: Starting work in the takeaway restaurant.

Strip 3: Getting to know the taxi drivers at the base (speaking 'Pahari').

Strip 4: The fight with a co-worker (using English to discriminate against Mirpuri-born migrants and swearing in 'Pahari').

Strip 5: Getting to know the co-worker from Gujranwala (speaking Urdu). 
Usman had started work in the takeaway and taxi office and was developing relationships with his colleagues. There were five strips in this trajectory. One of the strips revealed that Usman had had a physical fight with a 'British-born' co-worker who 'went beserk' when Usman had responded to his mocking him for being new to the country. The analysis of this strip revealed that English was being used by what Usman called the 'British-borns' as a means of intra-ethnic discrimination where these young men of Pakistani-heritage refused to use Punjabi and sought to bully their co-workers who, like Usman, had arrived in the UK via marriage migration. Organizing the data into strips brings together these disparate parts of different interviews and field notes into a timescale that reveals, for example, that when Usman is posting online from the taxi office he is also using spoken Pahari with the men in the taxi office while some of the 'British-borns' used English to distance themselves from the Mirpur-born migrants. The strips also enabled me to analyse my field notes alongside the interview data and establish how lonely Usman was feeling when I visited him at home as he had not made any friends outside the immediate family.

\section{Results}

In the following extracts, bold indicates English, italics indicate Urdu, and bold italics indicate Punjabi. Usman's translation in English appears in parentheses after the original comment.

\section{Part 1: Focus on Urdu and Mirpuri Punjabi}

In this section, I analyse the Facebook postings of Usman (in Lancashire) and his close friend Salman (in Mirpur). This was part of a longer sequence between Usman and seven interactants online made up of friends and family from across the world but most of whom were living in Mirpur and all of whom were posting in response to a picture that Usman had posted on Facebook of him shopping in the Trafford Centre mall just outside Manchester and approximately a 50 min drive from Usman's home. The data extracts presented below were analysed elsewhere (Capstick 2016a), but in the new analysis, translanguaging and heteroglossia are the focus of the investigation.

Part 1 Posting: trafford

1. Salman: teri o phet gaya ha tou to: $P$ (you look 'spoiled': P)

2. Usman: Pai ji kha pi kay say jao to yehi hoga na lol (this is what happens when you eat too much and go to sleep lol)

3. Salman: aho a $v$ gal sahi ha ahir d... ka yahi kam to hota khata peta $n$ sata (that's true, after all, that's all there is to do, eat, drink and sleep)

4. Salman: tou abi tk jag raha ha? Ghar ki chokidari: P (Why are you still up? Are you nightguarding: P)

5. Usman: Kutay job pe hun haraami (Dog I'm at the job bastard)

6. Salman: chokidari ki job gud job pc ktna pound kma raha ha? (It's a gud job of nightwatchman you know how many pounds are you earning from that?)

The extract begins with an exchange between Salman and Usman in Mirpuri Punjabi in Roman script. Mirpuri is not often found written in public domains because it is an informal spoken variety that does not carry the same prestige, outside domestic contexts, as Urdu or English. Given that Mirpuri Punjabi is a spoken variety rarely written down by its users, literacy in this variety is rarely found in public settings. It is rarely afforded the same prestige of Urdu or English away from domestic settings. For these reasons, Sabiha Mansoor (1993) set out the case that this lack of prestige of Punjabi has resulted in cultural alienation for many of the Punjabis of Punjab, but it would seem that something quite different is happening here where the use of Punjabi in Roman script connects Usman to his Azad Kashmiri culture rather than alienates him from it. The formal translation here is markedly different to Usman's translation of 'spoiled'. Phet, meaning 'torn open' and teri, meaning 'yours', with the omission of the term 'anus' for reasons of politeness, suggests that Usman wished to shield me from the exact meaning of Salman's comment. The profanity here would be seen as a special kind of discourse by Bakhtin, that of the 
language of the carnival (1968). Grotesque realism is the specific aspect of the language of the carnival that is useful here, where Bakhtin talks of myriad expressions of abuse and mockery filled with bodily images, at once positive and negative (Bakhtin 1981). 'Eating too much and drinking too much' is further evidence of this tradition.

A mixture of different voices are invoked here. In the online data, there is the voice of Salman which is strong and lewd. It is the voice of men appropriating a Punjabi idiom to make a humorous insult and is gendered as it is made appropriate by knowing what males can do and say, and therefore be, in Punjabi. It consolidates the friendship as this insult could only be seen as humorous between close friends. Indeed, Usman told me that Salman uses Punjabi here as he is 'the close one' meaning that he was a very close friend of Usman (evidenced in my field notes from the times I had met Salman in Mirpur). Thus, Salman mobilises these voices to sustain his friendship with Usman. The analysis here shows how when translanguaging, the men do not simply mix languages or codes but also mix different voices which index the particular demands of the communicative situation, that is, Salman's attitude towards Usman's appearance immediately after his arrival in the UK. Usman, in response, goes so far as to endorse Salman's comment by suggesting that 'this is what happens when you eat too much and go to sleep lol'. He chooses not to refute the insult but is instead conciliatory, using Mirpuri Punjabi to do this as he too is managing this transnational relationship and wishes to sustain the friendship. This is translanguaging but it is embedded in Usman's writing online as he uses a Roman script for Mirpuri Punjabi thereby acting on the different affordances of language varieties as well as the affordances of the technology. However, this is a different voice to the one he invokes when translating the interaction to me. Wishing to protect me from Salman's crudeness, and possibly the negative perspective on his own migration, Usman tells me in the self-report interview that Salman suggests that he looks 'spoiled' and later 'like a couch potato'. These are not accurate translations of Salman's words, but how would Usman confer the cultural meanings that are embedded in Salman's insult to me in the specific context of our interview and the asymmetry of our own relationship? Instead of a direct translation, Usman invokes a voice that suggests that he looks well and content, the opposite to Salman's perspective. Perhaps Usman wished that he did look spoiled having just arrived in the UK and was just beginning to settle into his new life. Thus the everyday translanguaging of Salman and Usman is taken up online in the primary voice of two close friends while other voices about Usman's distress can also be heard as the friends negotiate their response to having been separated by migration.

\section{'chokidar'}

From line 6 onwards, the main voice one hears from Salman and Usman is the popular urban cultural forms of Urdu which, like Punjabi above, has been transliterated from Perso-Arabic script (the script the men learned at school) to a Latin orthography which they, and their peers, have created as part of their vernacular response online. Within this primary voice, there are other voices: the humorous teasing of Salman about Usman's migration and the kind of work Usman is engaged in. Translanguaging can be seen in the negotiation of the 'chokidar' identity: Salman invokes a playful voice that imposes this identity on Usman, but it is in the wider context of Usman's migration that this invocation takes its meaning. Salman jokes about whether Usman is a 'chokidar' because he is up late even though he knows that Usman is already working in the taxi office and the takeaway restaurant. The term 'chokidar' is used in South Asia for low-waged watchmen who guard buildings and homes. The tone is friendly and suggests that Salman is again teasing Usman as he tells him to go to sleep. This is marked by such linguistic means as the use of the interrogative followed by a command which connotes concern, though Salman knows full well that Usman cannot go to sleep as he is at work. Maintaining the non-standard romanised orthography for Urdu, Usman's replies signal his annoyance, calling Salman a dog and a bastard. Invoking these identities in what Usman calls 'slang Urdu' enables Usman to use popular forms of abuse which may have seemed out of place in Englishwhich is the variety he chooses for the word 'job'. Salman invokes a similar voice when he 
responds by asking how much money Usman is making from this 'gud job'. Thus it seems that one main primary voice, slang Urdu, is invoked as it is appropriate for their banter as it provides the men with a level of informality to joke with each other while the second main primary voice, a romanised script for Urdu, is invoked as it connects them to the wider vernacular literacy practices which they use creatively online and on their mobile phones. These two voices are moulded together as a combined resource that enables the men to sustain their friendship while also commenting on Usman's migration. Seeing this banter as heteroglossic highlights the traces of the social and economic reasons for what Usman calls his 'economic migration' but what UK governments see as unwanted low-skilled migration from South Asia sustained through arranged marriages. The 'chokidar' identity playfully imposed by Salman could only be seen as a 'gud job' when it is translated into 'nightguard' as that term connotes a formal salary in the UK rather than the unregulated informal economy which many chokidars in Pakistan are part of. Thus within the primary voices of romanised slang Urdu, a multitude of other voices can be heard that signal hybrid identities about being a guard, as well as ideological stances on what it means to be a Pakistani migrant in the UK and the kinds of employment and salaries that are available to those migrants. This is another instance of the Carnivalesque where the lower classes are exulted as Usman enters the contradictory world of becoming (Bakhtin 1981, p. 234) as he transcends socio-economic categorisation in his new employment in the UK. The humour invokes these new socio-political realities of being a migrant guard in the UK and not being a chokidar in Pakistan which is evidence that translanguaging 'generates new identities, values and practices' (Garcia and Wei 2014, p. 24). The new practices here are the transnational literacies that Usman and Salman create to maintain and extend their friendship. They are made up of new orthographies, new values about what it means to leave one's home to take up a 'gud job' in England at the expense of leaving behind friends and new ideologies which both men invoke as they work out how they feel about Usman's migration within the context of transnational migration. These ideologies both shape the men's language practices and are shaped by them when they bring these resources together online.

\section{Conclusions}

The analysis of how transnational migrants make choices about how to use the language varieties that are available to them revealed that their decisions rely as much on their wider, gendered, cultural and social practices as they do on what scripts they were taught in at school. This analysis also demonstrates that the configurations of choice of script, style and register can be seen as evidence of everyday translanguaging as the findings in this paper demonstrate how Mirpuri migrants mix varieties from their repertoires and select different features of language when maintaining different transnational relations. This is evidence that the purpose of literacies shift as migrants take up different literacies at various points on their migration trajectories, shaping these literacies to fit with the purpose of the interaction and the social relations between those involved by appropriating, resisting and adhering to the style, genre and script conventions that are meaningful to them at the time. However, this view is expanded when these literacies are explored through the lens of heteroglossia which traces the different voices that are invoked at different historical moments in the trajectories of utterances. This analysis was enabled by constructing a methodological framework that traces the shifts in migrants' identities by tracing how different voices are invoked when migrants translanguage. Taking this approach reveals how interactants on Facebook were able to 'soft assemble' different script choices and language varieties when they experiment with written language. While the lens of heteroglossia puts the focus on the different voices present in migrants' literacies, seeing these literacies as translanguaging puts the emphasis on how migrants mobilise these different voices to orient to the new socio-political realities of their migrations. Lillis suggested that writing involves using existing available resources in terms of languages, materials and technologies that are bound up with their histories of use (Lillis 2013, p. 121). 
The way of capturing this use in this paper was to see these resources as part of migrants' everyday translanguaging when seeking to understand the nature of such resources as, Lillis argued, how, where and why they are used is a key dimension to the mobility of the resources (Lillis 2013). Tracing this mobility aids the conceptualisation of how bilinguals generate new literacies by drawing on both the dominant, such as standard British English, and non-dominant, such as slang Urdu, varieties in their repertoires and how they generate new romanised scripts for slang Urdu and Mirpuri Punjabi. Though Rahman (2011, pp. 222-25) showed how Urdu, Hindi and Punjabi have been written in Roman script since colonial rule, the analysis of Usman's insider perspective reveals how these practices are not solely supported by institutions such as school.

Sebba suggested that 'this choosing between options, whether conscious or unconscious, constitutes the 'practice' of writing system use; and sticking diligently to the prescribed standard is no less a practice than pointedly deviating from it' (Sebba 2009, p. 38). Though Standard British English is drawn on by Usman to help him fit into his new family, he and his friends also integrate standard with non-standard varieties such as 'slang' Urdu. This underscores the importance of heterogeneous minority language varieties in maintaining integration in a range of sites and in asserting collective identities which are available transnationally. In chokidar, Usman's comments are in the dialects of his heritage, as evidenced in the orthographic representation of dialect features such as slang Urdu. While in Poor Noor, the dialects are used to claim a transnational identity in which 'he is better now been through operation he is good now' is cast in English. For Androutsopoulos (2014), two different languages indexing two different identities moulded together into one post is heteroglossic, while in this paper, I argue it is not that there are two different languages that make this heteroglossic but rather it is how Usman mobilises different voices for different purposes as a vernacular response to the social distribution of these varieties in different sites that make his writing online heteroglossic. It is the case that computer-mediated discourses are 'sites of tension and contrast between linguistic resources, social identities and ideologies' (Androutsopoulos 2014, p. 283). However, what the discussion in the current paper hopes to highlight is how migrants resolve some of these tensions in the specific combinations of different voices that they put together to maintain transnational ties in their everyday translanguaging online.

Funding: This research received no external funding.

Institutional Review Board Statement: The study was conducted according to the guidelines of the Declaration of Helsinki, and approved by the Ethics Committee) of the University of Lancaster UK (ethical consent approved in May 2010).

Informed Consent Statement: Informed consent was obtained from all subjects involved in the study.

Data Availability Statement: Data not available publicly.

Conflicts of Interest: The author declares no conflict of interest.

\section{References}

Androutsopoulos, Jannis. 2014. Mediatization and sociolinguistic change: Key concepts, research traditions, open issues. In Mediatization and Sociolinguistic Change. Edited by Jannis Androutsopoulos. Berlin: Mouton De Grutyer, pp. 3-48.

Ayres, Alyssa. 2009. Speaking Like a State: Language and Nationalism in Pakistan. Cambridge: Cambridge University Press.

Bakhtin, Mikhail. 1981. The Dialogic Imagination: Four Essays. Edited by Michael Holquist. Translated by Caryl Emerson, and Michael Holquist. Texas: University of Texas Press.

Bakhtin, Mikhail. 1994. Problems of Dostoevsky's Poetics. In The Bakhtin Reader. Selected Writings of Bakhtin, Medvedev and Voloshinov. Edited by Pam Morris. London: Arnold, pp. 110-13.

Barton, David, and Mary Hamilton. 1998. Local Literacies. London: Routledge.

Barton, David, and Carmen Lee. 2013. Language Online: Investigating Digital Texts and Practices. London: Routledge.

Baynham, Mike, and Mastin Prinsloo, eds. 2009. The Future of Literacy Studies. Basingstoke: Palgrave Macmillan.

Blackledge, Adrian, and Angela Creese. 2014. Heteroglossia as practice and pedagogy. In Heteroglossia as Practice and Pedagogy. Edited by Adrian Blackledge and Angela Creese. London: Springer, pp. 1-21. 
Blackledge, Adrian, and Angela Pavlenko. 2001. Negotiation of identities in multilingual contexts. International Journal of Bilingualism 5: 243-59. [CrossRef]

Blommaert, Jan. 2008. Grassroots Literacy. London: Routledge.

Bloome, David. 2012. Classroom Ethnography. In Language, Ethnography and Education. Edited by David Bloome, Michael Grenfell, Kate Pahl, Jennifer Roswell and Brian Street. London: Routledge.

Bourdieu, Pierre, and Richard Nice. 1980. The production of belief: Contribution to an economy of symbolic goods. Media, Culture $\mathcal{E}$ Society 2: 261-93.

Canagarajah, Athelstan Suresh, ed. 2013. Literacy as Translingual Practice: Between Communities and Classrooms. London: Routledge.

Capstick, Tony. 2016a. Multilingual Literacies, Identities and Ideologies: Exploring Chain Migration from Pakistan to the UK. Basingstoke: Palgrave Macmillan.

Capstick, Tony. 2016b. Literacy mediation in marriage migration from Pakistan to the United Kingdom: Appropriating bureaucratic discourses to get a visa. Discourse E Society 27: 481-99.

Capstick, Tony. 2020. Transnational literacies as social remittances: The role of language ideologies in shaping migrants' online literacies. Applied Linguistics 41: 301-19. [CrossRef]

Fairclough, Norman. 1992. Discourse and text: Linguistic and intertextual analysis within discourse analysis. Discourse $\mathcal{E}$ Society 3 : 193-217.

Garcia, Ofelia. 2009. Bilingual Education in the 21st Century: A Global Perspective. Malden: Wiley-Blackwell.

Garcia, Andrea, and Amy Gaddes. 2012. Weaving language and culture: Latina adolescent writers in an after-school writing project. Reading \& Writing Quarterly 28: 143-63.

Garcia, Ofelia, and Naomi Kano. 2014. Translanguaging as process and pedagogy: Developing the English writing of Japenese students in the US. In The Multilingual Turn in Languages Education: Opportunities and Challenges. Edited by Jean Conteh and Gabriela Meier. Bristol: Multilingual Matters.

Garcia, Ofelia, and Li Wei. 2014. Translanguaging: Language, Bilingualism and Education. Basingstoke: Palgrave Macmillan.

Goffman, Erving. 2002. The Presentation of Self in Everyday Life. Garden City: Penguin, vols. 259.

Goodhart, David. 2013. The British Dream: Successes and Failures of Post-War Immigration. London: Atlantic Books.

Hanks, William. 2005. Explorations in the deictic field. Current Anthropology 46: 191-220. [CrossRef]

Harriss, Kaveri, and Alison Shaw. 2008. Kinship obligations, gender and the life course: Re-writing migration from Pakistan to Britain. In Pakistani Diasporas: Culture, Conflict, and Change. Edited by Virinder S. Kalra. Oxford: Oxford University Press, pp. $19-42$.

Heller, Monica. 2007. Bilingualism as ideology and practice. In Bilingualism: A Social Approach. Edited by Monica Heller. Basingstoke: Palgrave Macmillan, pp. 1-24.

Hua, Zhu, and Li Wei. 2020. Translanguaging, identity, and migration. In The Routledge Handbook of Language and Intercultural Communication. London: Routledge, pp. 234-48.

Jones, Rodney. 2016. Spoken Discourse. London: Bloomsbury.

Kell, Catherine. 2009. Literacy practices, text/s and meaning making across time and space. In The Future of Literacy Studies. Edited by Mike Baynham and Mastin Prinsloo. Basingstoke: Palgrave Macmillan, pp. 75-99.

Levitt, Patricia. 2015. Social Remittances: How migrating people drive migrating culture. In Routledge Handbook of Immigration and Refugee Studies. London: Routledge, pp. 247-52.

Lewis, Cynthia, and Bettina Fabos. 2008. Instant messaging, literacies, and social identities. In Handbook of Research on New Literacies. Edited by Coiro Julie, Knobel Michelle, Lankshear Colin and Leu Donald. New York: Routledge.

Lillis, Teresa. 2013. The Sociolinguistics of Writing. Edinburgh: Edinburgh University Press.

Lothers, Laura, and Michael David Lothers. 2007. Pahari and Pothwari: A Socioilinguistic Survey (FLI Language and Culture Series, 2). Peshawar: Frontier Language Institute.

Mansoor, S. 1993. Punjabi, Urdu, English in Pakistan. Lahore: Vanguard.

Marcus, George. 1995. Ethnography in/of the world system: The emergence of multi-sited ethnography. Annual Review of Anthropology 24: 95-117. [CrossRef]

Portes, Alejandro, Luis E. Guarnizo, and Patricia Landolt. 1999. The study of transnationalism: Pitfalls and promises of an emergent research field. Ethnic and Racial Studies 22: 217-37. [CrossRef]

Rahman, Tariq. 2011. From Hindi to Urdu: A Social and Political History. Karachi: Oxford University Press.

Rampton, Ben. 1995. Crossing. Language and Ethnicity among Adolescents. Harlow: Longman.

Rampton, Ben. 1998. Speech Community. In Handbook of Pragmatics. Edited by Verscheuren Jef, Ostman Jan-Ola, Blommaert Jan and Bulcran Chris. Amsterdam: John Benjamins, pp. 1-30.

Rampton, Ben. 2006. Language in Late Modernity: Interaction in an Urban School. Cambridge: Cambridge University Press.

Sebba, Mark. 2009. Sociolinguistic approaches to writing systems research. Writing Systems Research 1: 35-49. [CrossRef]

Soler, Josep, and Anastassia Zabrodskaja. 2017. New spaces of new speaker profiles: Exploring language ideologies in transnational families. Language in Society 46: 547-66. [CrossRef]

Street, B. 1984. Literacy in Theory and Practice. Cambridge: Cambridge University Press.

Velasco, Patricia, and Ofelia Garcia. 2014. Translanguaging and the writing of bilingual learners. Bilingual Research Journal 37: 6-23. [CrossRef]

Vertovec, Stephen. 2009. Transnationalism. Abingdon: Routledge. 
Warriner, Dorris S. 2007. Transnational literacies: Immigration, language learning, and identity. Linguistics and Education 18: 201-14. [CrossRef]

Wei, Li. 2011. Multilinguality, Multimodality and Multicompetence: Code- and Mode-Switching by Minority Ethnic Children in Complementary Schools. Modern Language Journal 95: 370-84. [CrossRef]

Wei, Li, ed. 2014. Applied Linguistics. New Jersey: Wiley-Blackwell.

Wodak, Ruth, and Salomi Boukala. 2015. (Supra)national identity and language: Rethinking national and European migration policies and the linguistic integration of migrants. Annual Review of Applied Linguistics 35: 253-73. [CrossRef] 